\title{
Plant age affects intraspecific variation in functional traits
}

\author{
Jonathan J. Henn (iD) Ellen I. Damschen
}

Received: 26 October 2020/Accepted: 1 April 2021/Published online: 12 April 2021

(C) The Author(s) 2021

\begin{abstract}
Functional traits are often used to examine ecological patterns and processes. Ontogeny-changes that occur over time as the result of developmentgenerates variation in traits within individual organisms. We aimed to quantify the role of ontogeny in structuring functional trait variation across a range of co-existing herbaceous perennial species and hypothesized that ontogenetic variation in traits would be greater in younger vs. older plants. We grew eight herbaceous perennial forb species common in tallgrass prairies from seed in a greenhouse in Madison, Wisconsin, USA to determine how and when time-related variation in functional traits is large relative to other sources of variation, such as differences between leaves and species. We destructively measured common functional traits on four individuals of each species every two weeks for 19 weeks, including leaf mass fraction, root mass fraction, stem mass fraction, specific leaf area, leaf dry matter content, and leaf area. We
\end{abstract}

Communicated by Bradley J. Butterfield.

Supplementary Information The online version contains supplementary material available at https://doi.org/10.1007/ s11258-021-01136-2.

J. J. Henn $(\bowtie) \cdot$ E. I. Damschen

Department of Integrative Biology, University of

Wisconsin-Madison, Madison, WI, USA

e-mail: henn.jonathan@gmail.com

J. J. Henn

Department of Biological and Environmental Sciences, University of Gothenburg, Gothenburg, Sweden found that most functional traits indeed change through time, that the direction of many changes are consistent between species but the magnitude of change is species specific, and most time-related variation occurred earlier in development. These results emphasize the importance of considering sampling timing and differences between young and old plants when measuring functional traits. Our results suggest that ontogenetic intraspecific variation can be substantial, especially early in life. It may be problematic to use traits measured from mature plants to interpret the importance of processes that occur at earlier life stages or vice versa; using seedling traits to understand adult plant responses may also be inappropriate.

Keywords Biomass allocation - Intraspecific variation · Ontogeny · Plant functional traits · Prairie plants

\section{Introduction}

Widespread shifts in environmental conditions due to habitat loss and fragmentation, climate change, and species invasions are requiring a more predictive ecology to maintain and restore biodiversity and ecosystem functions. Understanding the effects of functional traits on individual plant fitness is a promising approach for explaining and predicting likely responses to changes based on measurable and 
generalizable characteristics that influence growth, survival, and reproduction strategies of organisms (Violle et al. 2007; Funk et al. 2017). However, the use of trait-based approaches for addressing outstanding ecological questions largely depends on the extent to which functional traits vary across levels of organization (Violle et al. 2012; Shipley et al. 2016).

Variation in functional traits can come from multiple sources at several scales. While traditional approaches to functional ecology assume that species differences are most important, recent research indicating that intraspecific variation accounts for approximately $30-40 \%$ of the observed variation in functional traits has generated interest in examining sources of intraspecific variation (Albert et al. 2010a, b; Jung et al. 2010; Violle et al. 2012; Siefert et al. 2015). Understanding the sources of intraspecific variation in functional traits is critical for accurately using functional traits in community (Laughlin et al. 2012) and ecosystem models (Lavorel and Garnier 2002). There is substantial effort to characterize how factors, such as local adaptation, phenotypic plasticity (Bradshaw 2006; Nicotra et al. 2010; Mitchell and Bakker 2014), and environmental conditions (Cornwell and Ackerly 2009; Dwyer et al. 2014), contribute to variation in functional traits at the intraspecific level. However, ontogeny, or changes that occur due to the process of development, can be a source of variation in functional traits (Lusk and Warton 2007; González-Varo and Traveset 2016; Damián et al. 2018; Dayrell et al. 2018) that has received relatively less attention than environmentally driven intraspecific variation.

The implications of ontogenetic variation for plant survival strategies have been well studied. The relative importance of resource availability, species interactions, and abiotic conditions shift through time as plants age, causing resultant changes in plant strategies. These changes are reflected in biomass allocation patterns (McConnaughay and Coleman 1999; Poorter et al. 2012), stress tolerance strategies (CavenderBares and Bazzaz 2000; Boege and Marquis 2005), competition and facilitation dynamics (Schiffers and Tielbörger 2006; Le Roux et al. 2013), and responses to environmental changes (Parrish and Bazzaz 1985; Niinemets 2004, 2005; Moriuchi and Winn 2005). These ontogenetic shifts in life history strategies are also important for predicting how plants and other organisms respond to changing environments as individuals may be more or less sensitive to certain stresses at different times in development (Yang and Rudolf 2010).

While we know that ontogeny affects plant strategies, previous studies have not often directly examined relationships between ontogeny and functional traits, especially at a community scale. There is evidence that plants tend to shift from "faster" to "slower" growth and nutrient use strategies on the leaf economics spectrum (e.g., decreased specific leaf area, decreased leaf Nitrogen, and increased leaf dry matter content Wright et al. 2004) with age (Wright et al. 2004; Mason et al. 2013; Reich 2014) and through growing seasons (Fajardo and Siefert 2016). Plants also tend to invest proportionally more into stems compared to leaves through time (Poorter et al. 2012). However, previous studies of functional trait variation due to ontogeny tend to focus on one or few closely related species, measure only a few developmental stages, and use cross-sectional approaches rather than longitudinal studies (i.e., tracking individuals over time). These limitations make it difficult to determine whether the observed variation in traits is due to the environment or plant development (Niinemets 2004, 2005; Maherali et al. 2009; Mason et al. 2013; Mason and Donovan 2015; Damián et al. 2018). Also, previous studies have not quantified trait variation due to ontogeny relative to other potential sources of intraspecific trait variation. The lack of continuous functional trait measurements through time for a variety of co-existing species make it very difficult to study the effects of ontogeny on functional traits. More specifically, we do not fully understand whether ontogenetic functional trait changes are consistent between species, when ontogenetic variation in traits is the greatest, and the importance of ontogeny relative to other sources of intraspecific variation (i.e., genetic variation, phenotypic plasticity, and environmental differences that generate differences between individuals and leaves).

A lack of understanding of the ontogenetic variation in functional traits both within and between species could have large implications in the application of functional traits to predicting individual and community processes. Standard functional trait protocols prescribe measuring plant functional traits only on mature individuals and mature leaves (PérezHarguindeguy et al. 2013). However, focusing only on adult plant trait values may not accurately capture seedling and juvenile plant trait values, which affect 
germination and establishment. Since all adult plants have had to successfully germinate and establish, the reliance on adult plant trait measurements might result in mischaracterization of community assembly processes. Here, we assess ontogenetic changes in leaf and biomass investment functional traits for eight cooccurring herbaceous perennial grassland forb species to fill gaps in our understanding on the consistency, timing, and relative importance of ontogenetic trait variation. Specifically, we ask the following: (1) How do functional traits and correlations among functional traits change as plants age? (2) Are ontogenetic changes similar between plant species that vary in their growth rate? (3) As plants develop, does the importance of variation due to development change relative to other sources of variation (i.e., variation between species, individuals, and leaves)? We hypothesize that (1) traits will change with plant age such that older plants will invest more in stem biomass and will have leaves with more resource-conservative characteristics, (2) that the magnitude of these changes will be dependent on species identity, as changes through time will depend on the resource requirements and growth patterns of each species, and (3) changes due to ontogeny will be the most important source of trait variation in younger plants relative to other sources of variation. Trait variation due to ontogeny will be lower in older plants. We conducted this experiment in a greenhouse to isolate the effects of age from other environmental effects. While this approach does not reflect the conditions experienced by plants in the field, it provides a controlled setting to ask if intraspecific trait variation changes with plant age.

\section{Methods}

To answer these questions, we conducted a greenhouse experiment where we grew eight common tallgrass prairie perennial herbaceous species (Table 1) for 19 weeks to quantify functional traits associated with biomass and nutrient allocation over time. We selected species with relatively high and low growth rates from four taxonomically related pairs to assess a range of growth rates and taxonomic groups (Table 1, three congeneric pairs and one confamilial pair). We selected species from four different families to examine whether variation in traits occurred within or between taxonomic groups. We used relative growth rates calculated during our experiment to categorize species growth rate category (faster vs. slower growth within each taxonomic group) in our models. Relative growth rate for each species was estimated as the linear slope of the log-transformed total dry mass of each species through time.

Seeds of each species were from single populations in the Midwestern USA and obtained from Everwilde nursery in Sand Creek, WI, USA in May 2016. Prior to germination, both the Asclepias and Solidago species were cold stratified for 30 days in a refrigerator at $3{ }^{\circ} \mathrm{C}$ in moist paper towels (following suggestions from Prairie Moon Nursery). All species seeds were sterilized by soaking in a $2 \%$ bleach solution for $5 \mathrm{~min}$ before being rinsed three times in distilled water after stratification to prevent unwanted mold growth during germination.

Stratified and sterilized seeds were sown in flats containing Promix potting media in June 2016 and placed in a greenhouse that was maintained near $21{ }^{\circ} \mathrm{C}$, the mean summer temperature for Madison, Wisconsin, USA. After seeds germinated, seedlings were planted in 4 by $21 \mathrm{~cm}$ cone pots and grown in these pots for four weeks. At the end of these four weeks, plants were transplanted into 15 by $60 \mathrm{~cm}$ pots. Plants were watered daily and fertilized weekly after six weeks of growth with 20:10:20 (nitrogen:phosphorus:potassium) liquid fertilizer with micronutrients. Pot locations in the greenhouse were randomized every two weeks over the growth period.

We made trait measurements by destructively harvesting a subset of each species through the study period. We made nine measurements starting one week after germination (June 23, 2016) and ending 20 weeks after germination (October 31, 2016). Trait measurements occurred every two weeks with the exception of the period following transplantation into large pots where we gave plants 4 weeks to recover from transplanting. Overall, we made three measurements pre-transplantation and six measurements posttransplantation. At each measurement point, we measured four replicate plants of each species. Before harvesting, plant height was measured from the soil to the tallest portion of the plant. Plants were then carefully extracted from their pots and excess potting media was removed by massaging away loose material then gently washing away other material to keep root systems intact. Following harvest, plants were kept 
Table 1 Study species and the characteristics used for species selection

\begin{tabular}{|c|c|c|c|}
\hline Family & Genus & Species & Relative growth rate $\left(\mathrm{g} \mathrm{g}^{-1}\right.$ day $\left.^{-1}\right)$ \\
\hline \multirow[t]{2}{*}{ Asclepiadaceae } & Asclepias & incarnata $\mathrm{L}$. & $0.075 \pm 0.003$ \\
\hline & Asclepias & syriaca $\mathrm{L}$. & $0.068 \pm 0.003$ \\
\hline \multirow[t]{2}{*}{ Asteraceae } & Solidago & canadensis $\mathrm{L}$. & $0.090 \pm 0.003$ \\
\hline & Solidago & nemoralis Aiton & $0.070 \pm 0.003$ \\
\hline \multirow[t]{2}{*}{ Fabaceae } & Desmodium & canadense L. (DC) & $0.069 \pm 0.003$ \\
\hline & Desmodium & lllinoense A. Gray & $0.063 \pm 0.003$ \\
\hline \multirow[t]{2}{*}{ Lamiaceae } & Monarda & fistulosa $\mathrm{L}$. & $0.093 \pm 0.004$ \\
\hline & Pycnanthemum & virginianum $\mathrm{L}$. & $0.078 \pm 0.004$ \\
\hline
\end{tabular}

Each pair contained one faster and one slower growth rate as determined by relative growth rate. Relative growth rates were estimated from our data as the slope of the log-transformed dry mass of the whole plant through time using linear models and include standard error estimates

moist in plastic bags in a refrigerator and all traits were measured within $48 \mathrm{~h}$.

We measured traits that correspond to allocation in biomass (leaf area $\left(\mathrm{cm}^{2}\right)$, leaf mass fraction, stem mass fraction, and root mass fraction) (Poorter et al. 2012) and leaf carbon economy (specific leaf area $\left(\mathrm{cm}^{2} \mathrm{~g}^{-1}\right)$ and leaf dry matter content $\left.\left(\mathrm{g} \mathrm{g}^{-1}\right)\right)$. To measure biomass allocation, roots, stems, leaves, flowers, and fruit were separated, weighed for fresh mass, and then dried at $55{ }^{\circ} \mathrm{C}$ for at least $72 \mathrm{~h}$ before dry masses were measured. To measure leaf area, five healthy, fresh leaves were scanned or photographed to calculate leaf area using ImageJ (Schneider et al. 2012). If present, cotyledons were included as leaves.

\section{Analyses}

We used linear models to assess whether functional traits change as plants age and whether changes with age vary by species, growth rate, or taxonomic group (Questions 1 and 2). We modeled functional trait values as a function of plant age, growth rate category (faster vs. slower), taxonomic group (plant family), and all interactions. This model structure allows us to determine whether changes through time are related to taxonomic group, growth rate category, or are species specific. The three-way interaction between plant age, growth rate category, and taxonomic group allowed us to assess whether the relationship between trait values and age vary by species. While both plant size and plant age could influence functional trait values, plant size was highly correlated with plant age in our experiment, so chose to include only plant age in our models to avoid multicollinearity. Due to apparent non-linear responses between younger and older plants through time for some traits, we also ran separate models, including only the last six time measurements for all traits, and include these results in the supplemental materials (Supplemental Table 2 and Supplemental Figure 1).

We also assessed multivariate trait responses through time by performing a Principal Components Analysis (PCA) that included all measurements of all individuals of each species. This allowed us to quantify the position of each plant that was measured in multivariate trait space and use the mean score on each axis of all replicate plants of each species from each measurement point to plot how species move on average in multidimensional trait space through time.

Prior to analysis, all variables were assessed for normality. Leaf area and specific leaf area were log transformed to conform to linear model assumptions and to improve model performance (De Bello et al. 2011) and all leaf-level traits (leaf area, specific leaf area, and leaf dry matter content) were averaged by individual plant for analyses. Linear models were fit using the "lm" function and the PCA was fit using the "prcomp" function with centered and scaled values in R (RCoreTeam 2017).

Finally, to evaluate the importance of changes through time relative to other sources of variation and whether plant age affects ontogenetic variation (Question 3), we used a variance partitioning analysis across several nested levels. For biomass allocation traits, we 
analyzed how variance is partitioned between species, measurement times for each species (ontogeny), and individual plants in each measurement time. For leaflevel traits, we used the same groups with the addition of replicate leaves nested within each individual plant. This nested structure allowed us to separate variation that is associated with each nested level across the whole experiment. We also evaluated whether there are times in plant development when ontogenetic variation is more important compared to other sources of variation. We did this by separating our measurements into three periods, which each contains three measurement points. The first period includes the youngest plants (measurements 1-3), the second period contains measurements $4-6$, and the final period contains measurements 7-9. By separating our time-series into these periods, we can compare how the amount of variation in traits related to time changes through plant development.

\section{Results}

Ontogenetic shifts in traits

In all models, functional trait values shifted through time and in most cases, the magnitude of changes through time were species specific (Fig. 1; see supplemental Table 1 for model statistics). Observed changes were generally consistent with greater investment in stem biomass and resource-conservative leaves as plants aged. Leaf mass fraction decreased over time while stem mass fraction and leaf dry matter content tended to increase for most species, consistent with our hypotheses (Fig. 1). Specific leaf area showed a decreasing trend through the first three measurements followed by an increase after transplantation, which was followed by another decreasing trend (Fig. 1, Supplemental Figure 1). The shift in specific leaf area following transplantation corresponds to a marked increase in leaf area. In multivariate space, $\mathrm{PC} 1$ consistently increased through time for all species such that both stem mass fraction and leaf area increased along PC1 (Fig. 2; Table 2). The second and third principal components were not as closely related to shifts through time as PC1, but instead represented different investment in leaves and roots (PC2, Table 2) and in specific leaf area and leaf dry matter content (PC3, Table 2). Root mass fraction was the only trait that showed little evidence of consistent change through time.

Relative importance of ontogeny over time

When considering the entire measurement period of this study, variation related to change through time was very high for almost all traits that we measured, accounting for 35.6-90.8\% of trait variation (Table 3). However, when split into three periods, the timerelated variation tended to decrease while specieslevel variation tended to increase through time (Fig. 3). There was also an increase in variation between individuals within each species through time for some traits ("individual" variation, Fig. 3). By the end of this study, all traits except specific leaf area and leaf dry matter content showed most variation between species. Leaf dry matter content was the only trait where variation related to the species level was not maximized in older plants (Fig. 3). Total variation did not increase for any traits except specific leaf area and leaf area, indicating that older plants showed more variation in these traits (Fig. 3).

\section{Discussion}

Trait-based ecology is a powerful approach for understanding the mechanisms underpinning species life history strategies along with community and ecosystem dynamics. The utility of this approach depends on understanding whether functional traits change with ontogeny, whether those changes are predictable, and when such changes are most important over the course of development. We show that traits often vary through time; ontogenetic-related variation is species specific, but somewhat consistent between species for some traits. Finally, we show that ontogeny has a bigger impact on trait variation earlier rather than later in life.

\section{Ontogeny effects on functional traits}

Our assessment of eight perennial herbaceous prairie species that vary in growth rate and taxonomic group revealed that while most traits changed through time in species-specific ways, changes were primarily in the same direction, supporting our first hypothesis. We found a tendency toward increasing stem mass 

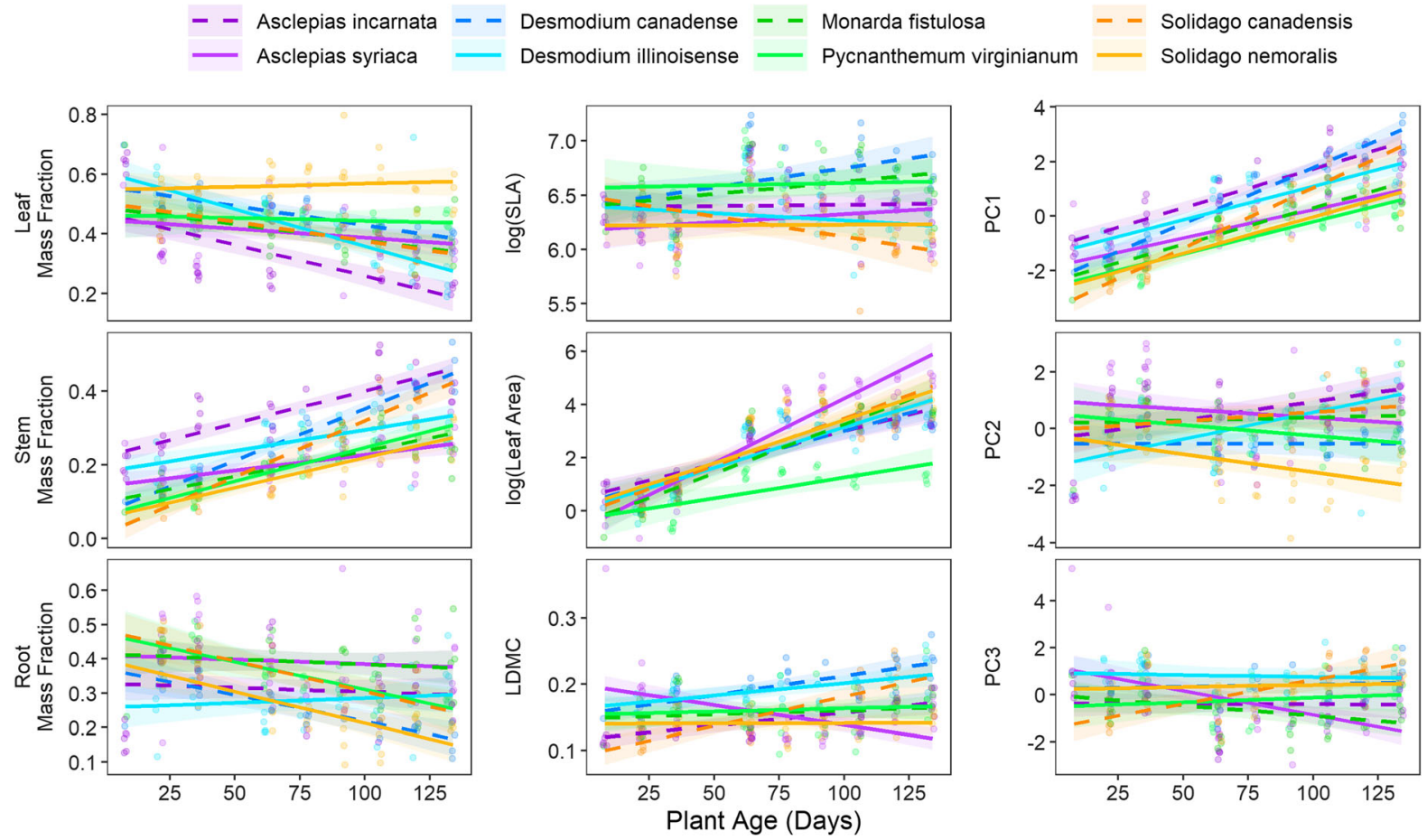

Fig. 1 Trait change trends over time for our eight study species. Lines indicate linear model fits for each species where dashed lines indicate species with faster growth rates while solid indicate species with slower growth rates and colors correspond

fraction as plants get larger, which is often observed as larger plants need to invest proportionally more into stems to support their leaves in positions that are exposed to sun (Poorter et al. 2012). Consistent changes along PC1 among all species further support the importance of changes in stem mass fraction as plants age. Like biomass allocation traits, leaf traits (specific leaf area and leaf dry matter content) also showed generally consistent linear changes through time. The decreases in specific leaf area and increases in leaf dry matter content correspond to a shift toward more conservative leaf strategies in older plants (Wright et al. 2004; Reich 2014) and is consistent with previous research (Mason et al. 2013; Gibert et al. 2016). There are several reasons why these temporal shifts in traits might be observed. First, these shifts toward more conservative leaf strategies when plants age may reflect a shift in importance in building stem structures that decrease the value of cheaply constructed leaves in larger plants (Givnish 1995). Second, plants tend to invest more into constitutive defenses later in life, which could explain the shift to different species. $S L A=$ specific leaf area and $L D M C=$ leaf dry matter content. Uncertainty intervals on each line indicate one standard error. PCA axes correspond to values shown in Fig. 2 and trait loadings on each PC are described in Table 2

toward tissues with more conservative traits (Barton and Koricheva 2010). Third, maximizing growth rates in seedlings can minimize time spent as vulnerable small plants, increasing the value of resource-acquisitive strategies in young plants, which must focus on establishment rather than competition or stress tolerance (Dayrell et al. 2018). Finally, while stress levels should not have changed in the greenhouse, this pattern may also be due to adaptations to increasing amounts of stress during the peak of summer under natural conditions with high heat, insect herbivory, and variable rainfall in temperate grasslands (Miller et al. 2018).

Trait values did not shift in the same way through time for all species and differences in growth rate could explain some of these differences. For example, some faster-growing species invested more in stems and leaf area compared to their slow-growing taxonomic pair (Fig. 1). These differences correspond to more change along PC1 (Fig. 2). These differences in strategy could have implications for community patterns by affecting the timing and strength of 


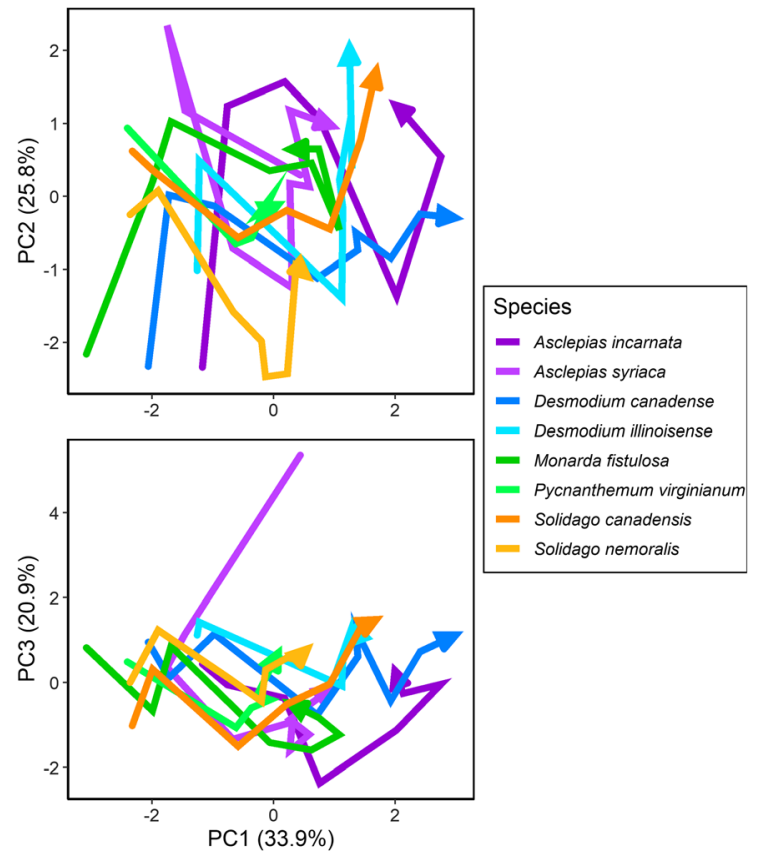

Fig. 2 Plots of change through time for each species in multidimensional trait space along combinations of principal components 1,2 , and 3 . The lines represent mean values along each principal component for each species at each measurement time. The arrows indicate the latest measurements (oldest plants), while the earliest measurements (youngest plants) are furthest from the arrows. For trait loadings on each axis, see Table 2

Table 2 Plant trait loadings on first three axes of PCA along with the proportion of variance explained by each principle component

\begin{tabular}{lrrr}
\hline Trait & \multicolumn{1}{c}{ PC1 } & \multicolumn{1}{c}{ PC2 } & \multicolumn{1}{c}{ PC3 } \\
\hline LMF & -0.30 & -0.68 & 0.22 \\
SMF & 0.66 & 0.08 & 0.04 \\
RMF & -0.35 & 0.61 & -0.34 \\
Leaf area & 0.52 & -0.11 & -0.25 \\
SLA & 0.17 & -0.28 & -0.60 \\
LDMC & 0.24 & 0.25 & 0.64 \\
Variance explained $(\%)$ & 33.9 & 25.8 & 20.9 \\
\hline
\end{tabular}

interactions between species and their environment. Under ideal conditions, greater increases in stem biomass will enable greater capture of light and a potential to outcompete other species for that resource. However, greater increases in stem mass fraction in the faster-growing species may simply be a
Table 3 Variation in functional traits related to nested levels of organization during 10 weeks of growth

\begin{tabular}{llllcll}
\hline Level & LMF & SMF & RMF & Leaf area & SLA & LDMC \\
\hline Species & 21.6 & 21.1 & 16.8 & $<0.001$ & 21.3 & 11.9 \\
Time & 51.8 & 64.2 & 47.8 & 90.8 & 41.8 & 35.6 \\
Individual & 26.6 & 14.6 & 35.5 & 0.6 & 13.7 & 19.9 \\
Leaf & - & - & - & 8.6 & 23.1 & 32.5 \\
\hline
\end{tabular}

Numbers indicate the percent of variation attributable to each level

$L M F$ leaf mass fraction, $S M F$ stem mass fraction, $R M F$ root mass fraction, SLA specific leaf area, and $L D M C$ leaf dry matter content

consequence of greater biomass accumulation, which often requires disproportionately greater investment in stems to support increased leaf area (Poorter et al. 2012). Also, while not related to variation in time, PCs 2 and 3 reveal traits that tend to covary (Table 2). PC2 shows that root mass fraction and leaf mass fraction are negatively related where increasing root investment tends to come at the expense of leaf rather than stem investment. PC3 shows that specific leaf area and leaf dry matter content are negatively correlated, which is a common trend that is the result of lower dry matter, generating lighter leaves relative to their leaf area.

Traits change faster in young plants

Variation related to time was the largest source of intraspecific variation at early stages in our study. This is similar to Damián et al. (2018) where older plants tended to have stronger correlations among functional traits, resulting in greater variation in younger plants. Our results also show that leaf area and specific leaf area total variation increases substantially through time (Figs. 1 and 3), so while the proportion of variation that is related to ontogeny decreases through time, this may not translate into a decrease in actual variation related to ontogeny. This is likely because older plants have more leaves of different ages and are therefore more variable. However, for other traits, there was no increase in overall variation through time and these results mean that measuring variation in young stages will likely be very important in characterizing young plant functional strategies. 


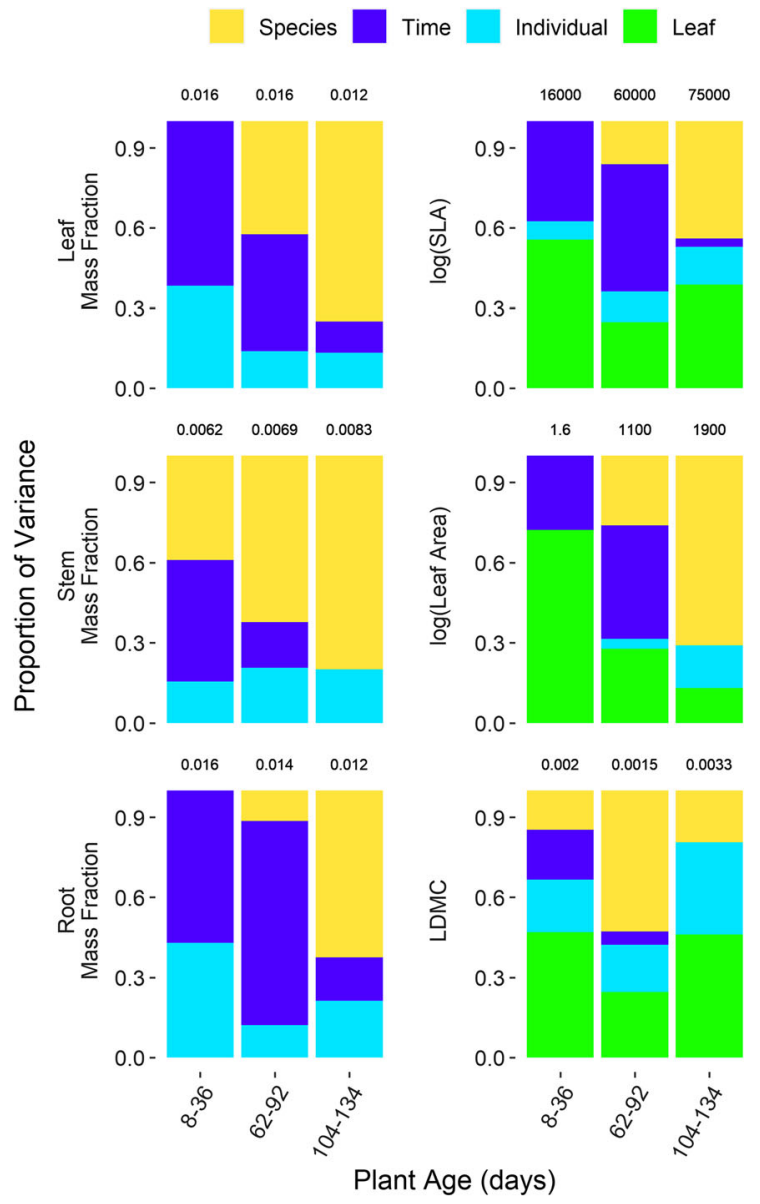

Fig. 3 Variance partitioning among nested levels of organization for traits during three periods of development. Species level indicates each species (eight species), time indicates measurement points within each period (three measurement points), individual indicates each plant measured (four replicate individuals in each measurement point), and leaf indicates replicate leaves from each individual plant (five replicate leaves per plant). Numbers above each bar indicate total variance in each trait during each period, while the height of each bar is normalized to sum to 1

Since seed germination and establishment are especially vulnerable stages, functional trait values taken from these early life stages are likely critical for understanding community composition and assembly (Poorter 2007; Larson et al. 2015). The traits of young plants should not be ignored because the relationships between functional traits and growth and survival can change between seedling, juvenile, and mature growth stages, as observed in tree communities (Quero et al. 2008; Spasojevic et al. 2014; Lasky et al. 2015). However, temporal variation in plant traits is rarely considered. Larson et al. (2015) developed a potential solution to capturing trait differences through time in young plants by using both early- and late-seedling traits to characterize the potentially rapid changes in functional trait values in young plants. This approach is likely to be especially important when considering traits that have strong changes through time like leaf area. On the other hand, choosing traits that are shown to be less dependent on development or environmental context (Kramer-Walter and Laughlin 2017) could aid in comparing species traits across space and through time. Another potential solution is decomposing the effect of time-related variation compared to other sources of variation to help in strategically selecting when traits should be measured and to select times where interspecific variation is maximized, as is assumed in many functional trait studies (Shipley et al. 2016; Funk et al. 2017). Finally, relaxing the requirement of measuring only mature, sun-exposed leaves would capture more variation related to both ontogeny and environmental conditions.

\section{Implications for trait-based plant ecology}

Our assessment of ontogenetic shifts in functional traits across eight co-occurring species that vary in growth rate and taxonomic group supports the importance of considering plant age when measuring functional traits. While this study focused on herbaceous species, differences between herbaceous and woody growth strategies also have an important effect on the predictions of ontogenetic trait variation due primarily to wood production (Poorter et al. 2012). We would expect that differences in traits related to ontogeny would be even more extreme for woody species because the environmental conditions and constraints can be substantially different between adult and sapling trees. Appreciating these ontogenetic differences in functional traits of trees could help explain variation in adult and sapling growth and survival (Spasojevic et al. 2014; Lasky et al. 2015; Paine et al. 2015).

All surviving plants in the wild had to have passed through the germination and young plant stage. Additionally, herbaceous plants in seasonal environments will resprout each year and must survive a stage when individuals are small and face different constraints than fully grown plants. Since our results show that young plants have different traits than older 
individuals, adult trait values are unlikely to reflect the traits of young plants, which could make adult trait measurements misleading when considering species recruitment or community assembly dynamics (Larson et al. 2015; Visser et al. 2016). Combining ontogenetic shifts in functional traits with variation in phenology and climate change also raises questions about the timing of species interactions (Yang and Rudolf 2010; González-Varo and Traveset 2016; Rudolf 2019). If the onset or speed of ontogeny is affected by climate change (e.g., emergence, growth rate, or flowering), the timing of trait expression could also change and result in novel interactions between species.

This study occurred in a greenhouse with controlled environmental conditions and water availability, which differs from natural field conditions. Plants grown in this study did not experience interactions with other plants, which could likely affect the phenotype of the plants. However, many of the trends that we observed are consistent with observations from field-based studies (Niinemets 2005; Mitchell and Bakker 2014; Spasojevic et al. 2014; Dayrell et al. 2018). Studies to better understand how ontogenetic trait development both influences and is influenced by species interactions should be a research priority.

\section{Conclusions}

Here we show how plant functional traits change with ontogeny. While the magnitude of ontogenetic changes in functional traits were species specific, the direction of change was mostly consistent for all species, suggesting predictable shifts through time in functional trait values. Overall, interspecific differences in traits were maximized (relative to intraspecific differences) when plants were older, supporting the importance of measuring mature individuals when seeking to compare traits between species (Cornelissen et al. 2003; Pérez-Harguindeguy et al. 2013). Our experiment indicates that measuring adult plant traits is appropriate for comparing species when they are mature, but that these same traits are not necessarily representative of the traits of young plants. Therefore, characterizing not only the trait values of mature plants but also how traits shift from juveniles to mature plants is important in capturing the complete survival strategy of a plant. This will be especially important for testing community assembly theory where early life stages play a crucial role and for predicting community dynamics, interaction outcomes, and environmental stability in a changing world (Wright et al. 2016; Rudolf 2019).

Acknowledgements The authors are grateful for the efforts of Genevieve Anderegg, Shea Collins, Auna Kauffman-Schwartz, Samantha Kinsler, and Samuel Saghafi in collecting data and the staff of the Walnut Street greenhouses at University of Wisconsin-Madison for their support during this experiment. They also thank the Damschen Lab members for feedback on the manuscript.

Author contributions Both authors designed study. JJH collected and analyzed data. JJH led and EID contributed to writing.

Funding Open access funding provided by University of Gothenburg. This work was supported by University of Wisconsin-Madison's Department of Integrative Biology summer research funding. This material is based upon work supported by the National Science Foundation Graduate Research Fellowship Program under Grant No. (DGE1747503). Any opinions, findings, and conclusions or recommendations expressed in this material are those of the author(s) and do not necessarily reflect the views of the National Science Foundation. Support was also provided by the Graduate School and the Office of the Vice Chancellor for Research and Graduate Education at the University of Wisconsin-Madison with funding from the Wisconsin Alumni Research Foundation.

Data availability All data and code associated with this manuscript are available at https://doi.org/10.17605/OSF.IO/ KHGM2.

\section{Declarations}

\section{Conflict of interest None.}

Consent for publication All the authors agree to the publication of this manuscript.

Open Access This article is licensed under a Creative Commons Attribution 4.0 International License, which permits use, sharing, adaptation, distribution and reproduction in any medium or format, as long as you give appropriate credit to the original author(s) and the source, provide a link to the Creative Commons licence, and indicate if changes were made. The images or other third party material in this article are included in the article's Creative Commons licence, unless indicated otherwise in a credit line to the material. If material is not included in the article's Creative Commons licence and your intended use is not permitted by statutory regulation or exceeds the permitted use, you will need to obtain permission directly from the copyright holder. To view a copy of this licence, visit http://creativecommons.org/licenses/by/4.0/. 


\section{References}

Albert CH, Thuiller W, Yoccoz NG, Douzet R, Aubert S, Lavorel S (2010a) A multi-trait approach reveals the structure and the relative importance of intra- vs. interspecific variability in plant traits. Funct Ecol 24:1192-1201. https://doi.org/10.1111/j.1365-2435.2010. 01727.x

Albert CH, Thuiller W, Yoccoz NG, Soudant A, Boucher F, Saccone P, Lavorel S (2010b) Intraspecific functional variability: extent, structure and sources of variation. J Ecol 98:604-613. https://doi.org/10.1111/j.1365-2745.2010. 01651.x

Barton KE, Koricheva J (2010) The ontogeny of plant defense and herbivory: characterizing general patterns using metaanalysis. Am Nat 175:481-493. https://doi.org/10.1086/ 650722

Boege K, Marquis RJ (2005) Facing herbivory as you grow up: the ontogeny of resistance in plants. Trends Ecol Evol 20:441-448. https://doi.org/10.1016/j.tree.2005.05.001

Bradshaw AD (2006) Unravelling phenotypic plasticity - why should we bother? New Phytol 170:644-648

Cavender-Bares J, Bazzaz FA (2000) Changes in drought response strategies with ontogeny in Quercus rubra: implications for scaling from seedlings to mature trees. Oecologia 124:8-18. https://doi.org/10.1007/PL00008865

Cornelissen J, Lavorel SB, Garnier EB, Díaz SC, Buchmann ND, Gurvich DEC, Reich PBE, Steege HF, Morgan HDG, MGAVDH A, Pausas JGH, Poorter HI (2003) A handbook of protocols for standardised and easy measurement of plant functional traits worldwide. Aust J Bot 51:335-380

Cornwell WK, Ackerly DD (2009) Community assembly and shifts in plant trait distributions across an environmental gradient in coastal California. Ecol Monogr 79:109-126. https://doi.org/10.1890/07-1134.1

Damián X, Fornoni J, Domínguez CA, Boege K (2018) Ontogenetic changes in the phenotypic integration and modularity of leaf functional traits. Funct Ecol 32:234-246. https://doi.org/10.1111/1365-2435.12971

Dayrell RLC, Arruda AJ, Pierce S, Negreiros D, Meyer PB, Lambers H, Silveira FAO (2018) Ontogenetic shifts in plant ecological strategies. Funct Ecol 32:2730-2741. https://doi.org/10.1111/1365-2435.13221

De Bello F, Lavorel S, Albert CH, Thuiller W, Grigulis K, Dolezal J, Janeček Š, Lepš J (2011) Quantifying the relevance of intraspecific trait variability for functional diversity. Methods Ecol Evol 2:163-174. https://doi.org/ 10.1111/j.2041-210X.2010.00071.x

Dwyer JM, Hobbs RJ, Mayfield MM (2014) Specific leaf area responses to environmental gradients through space and time. Ecology 95:399-410. https://doi.org/10.1890/130412.1

Fajardo A, Siefert A (2016) Phenological variation of leaf functional traits within species. Oecologia 180:951-959. https://doi.org/10.1007/s00442-016-3545-1

Funk JL, Larson JE, Ames GM, Butterfield BJ, Cavender-Bares J, Firn J, Laughlin DC, Sutton-Grier AE, Williams L, Wright J (2017) Revisiting the Holy Grail: using plant functional traits to understand ecological processes. Biol Rev 92:1156-1173. https://doi.org/10.1111/brv.12275
Gibert A, Gray EF, Westoby M, Wright IJ, Falster DS, Wilson S (2016) On the link between functional traits and growth rate: meta-analysis shows effects change with plant size, as predicted. J Ecol 104:1488-1503. https://doi.org/10.1111/ 1365-2745.12594

Givnish TJ (1995) Plant stems: biomechanical adaptation for energy capture and influence on species distributions. Elsevier, San Diego, CA

González-Varo JP, Traveset A (2016) The labile limits of forbidden interactions. Trends Ecol Evol 31:700-710. https:// doi.org/10.1016/j.tree.2016.06.009

Jung V, Violle C, Mondy C, Hoffmann L, Muller S (2010) Intraspecific variability and trait-based community assembly. J Ecol 98:1134-1140. https://doi.org/10.1111/j. 1365-2745.2010.01687.x

Kramer-Walter KR, Laughlin DC (2017) Root nutrient concentration and biomass allocation are more plastic than morphological traits in response to nutrient limitation. Plant Soil 416:539-550. https://doi.org/10.1007/s11104017-3234-9

Larson JE, Sheley RL, Hardegree SP, Doescher PS, James JJ (2015) Seed and seedling traits affecting critical life stage transitions and recruitment outcomes in dryland grasses. J Appl Ecol 52:199-209. https://doi.org/10.1111/13652664.12350

Lasky JR, Bachelot B, Muscarella R, Schwartz N, ForeroMontana J, Nytch CJ, Swenson NG, Thompson J, Zimmerman JK, Uriarte MM (2015) Ontogenetic shifts in traitmediated mechanisms of plant community assembly. Ecology 96:2157-2169. https://doi.org/10.1890/14-1809.1

Laughlin DC, Joshi C, van Bodegom PM, Bastow Z, a., Fulé PZ, (2012) A predictive model of community assembly that incorporates intraspecific trait variation. Ecol Lett 15:1291-1299. https://doi.org/10.1111/j.1461-0248.2012. 01852.x

Lavorel S, Garnier E (2002) Predicting changes in community composition and ecosystem functioning from plant traits: revisting the Holy Grail. Funct Ecol 16:545-556. https:// doi.org/10.1046/J.1365-2435.2002.00664.X

Le Roux PC, Shaw JD, Chown SL (2013) Ontogenetic shifts in plant interactions vary with environmental severity and affect population structure. New Phytol 200:241-250. https://doi.org/10.1111/nph.12349

Lusk CH, Warton DI (2007) Global meta-analysis shows that relationships of leaf mass per area with species shade tolerance depend on leaf habit and ontogeny. New Phytol 176:764-774. https://doi.org/10.1111/j.1469-8137.2007. 02264.x

Maherali H, Caruso CM, Sherrard ME (2009) The adaptive significance of ontogenetic changes in physiology: a test in Avena barbata. New Phytol 183:908-918. https://doi.org/ 10.1111/j.1469-8137.2009.02845.x

Mason CM, Donovan LA (2015) Does investment in leaf defenses drive changes in leaf economic strategy? A focus on whole-plant ontogeny. Oecologia 177:1053-1066. https://doi.org/10.1007/s00442-014-3177-2

Mason CM, McGaughey SE, Donovan LA (2013) Ontogeny strongly and differentially alters leaf economic and other key traits in three diverse Helianthus species. J Exp Bot 64:4089-4099. https://doi.org/10.1093/jxb/ert249 
McConnaughay KDM, Coleman JS (1999) Biomass allocation in plants: ontogeny or optimality? A test along three resource gradients. Ecology 80:2581-2593

Miller JE, Ives AR, Harrison SP, Damschen EI, Miller JD (2018) Early-and late-flowering guilds respond differently to landscape spatial structure. J Ecol 106:1033-1045. https:// doi.org/10.1111/1365-2745.12849

Mitchell RM, Bakker JD (2014) Intraspecific trait variation driven by plasticity and ontogeny in hypochaeris radicata. PLoS ONE. https://doi.org/10.1371/journal.pone.0109870

Moriuchi KS, Winn AA (2005) Relationships among growth, development and plastic response to environment quality in a perennial plant. New Phytol 166:149-158. https://doi. org/10.1111/j.1469-8137.2005.01346.x

Nicotra AB, Atkin OK, Bonser SP, Davidson AM, Finnegan EJ, Mathesius U, Poot P, Purugganan MD, Richards CL, Valladares F, van Kleunen M (2010) Plant phenotypic plasticity in a changing climate. Trends Plant Sci 15:684-692. https://doi.org/10.1016/j.tplants.2010.09.008

Niinemets U (2004) Adaptive adjustments to light in foliage and whole-plant characteristics depend on relative age in the perennial herb Leontodon hispidus. New Phytol 162:683-696. https://doi.org/10.1111/j.1469-8137.2004. 01071.x

Niinemets U (2005) Key plant structural and allocation traits depend on relative age in the perennial herb Pimpinella saxifraga. Ann Bot 96:323-330. https://doi.org/10.1093/ aob/mci180

Paine CET, Amissah L, Auge H, Baraloto C, Baruffol M, Bourland N, Bruelheide H, Daïnou K, de Gouvenain RC, Doucet JL, Doust S, Fine PVA, Fortunel C, Haase J, Holl KD, Jactel H, Li X, Kitajima K, Koricheva J, MartínezGarza C, Messier C, Paquette A, Philipson C, Piotto D, Poorter L, Posada JM, Potvin C, Rainio K, Russo SE, RuizJaen M, Scherer-Lorenzen M, Webb CO, Wright SJ, Zahawi RA, Hector A (2015) Globally, functional traits are weak predictors of juvenile tree growth, and we do not know why. J Ecol 103:978-989. https://doi.org/10.1111/ 1365-2745.12401

Parrish JAD, Bazzaz FA (1985) Ontogenetic niche shifts in oldfield annuals. Ecology 66:1296-1302

Pérez-Harguindeguy N, Díaz S, Garnier E, Lavorel S, Poorter H, Jaureguiberry P, Bret-Harte MS, Cornwell WK, Craine JM, Gurvich DE, Urcelay C, Veneklaas EJ, Reich PB, Poorter L, Wright IJ, Ray P, Enrico L, Pausas JG, De Vos AC, Buchmann N, Funes G, Quétier F, Hodgson JG, Thompson K, Morgan HD, Ter Steege H, Van Der Heijden MGA, Sack L, Blonder B, Poschlod P, Vaieretti MV, Conti G, Staver AC, Aquino S, Cornelissen JHC (2013) New handbook for standardised measurement of plant functional traits worldwide. Aust J Bot 61:167-234. https://doi. org/10.1071/BT12225

Poorter H, Niklas KJ, Reich PB, Oleksyn J, Poot P, Mommer L (2012) Biomass allocation to leaves, stems and roots: metaanalyses of interspecific variation and environmental control. New Phytol 193:30-50. https://doi.org/10.1111/j. 1469-8137.2011.03952.x

Poorter L (2007) Are species adapted to their regeneration niche, adult niche, or both? Am Nat 169:433-442. https:// doi.org/10.1086/512045
Quero JL, Gómez-Aparicio L, Zamora R, Maestre FT (2008) Shifts in the regeneration niche of an endangered tree (Acer opalus ssp. granatense) during ontogeny: using an ecological concept for application. Basic Appl Ecol 9:635-644. https://doi.org/10.1016/j.baae.2007.06.012

RCoreTeam (2017) R: a language and environment for statistical computing

Reich PB (2014) The world-wide "fast-slow" plant economics spectrum: a traits manifesto. J Ecol 102:275-301. https:// doi.org/10.1111/1365-2745.12211

Rudolf VHW (2019) The role of seasonal timing and phenological shifts for species coexistence. Ecol Lett 22:1324-1338. https://doi.org/10.1111/ele.13277

Schiffers K, Tielbörger K (2006) Ontogenetic shifts in interactions among annual plants. J Ecol 94:336-341. https://doi. org/10.1111/j.1365-2745.2006.01097.x

Schneider CA, Rasband WS, Eliceiri KW (2012) NIH image to ImageJ: 25 years of image analysis. Nat Methods 9:671-675

Shipley B, de Bello F, Cornelissen JHC, Laliberté É, Laughlin DC, Reich PB (2016) Reinforcing foundation stones in trait-based plant ecology. Oecologia 180:923-931. https:// doi.org/10.1007/s00442-016-3549-x

Siefert A, Violle C, Chalmandrier L, Albert CH, Taudiere A, Fajardo A, Aarssen LW, Baraloto C, Carlucci MB, Cianciaruso MV, de Dantas V, de Bello F, Duarte LDS, Fonseca CR, Freschet GT, Gaucherand S, Gross N, Hikosaka K, Jackson B, Jung V, Kamiyama C, Katabuchi M, Kembel SW, Kichenin E, Kraft NJB, Lagerström A, BagoussePinguet Y, Li Y, Mason N, Messier J, Nakashizuka T, Overton JM, Peltzer DA, Pérez-Ramos IM, Pillar VD, Prentice HC, Richardson S, Sasaki T, Schamp BS, Schöb C, Shipley B, Sundqvist M, Sykes MT, Vandewalle M, Wardle DA (2015) A global meta-analysis of the relative extent of intraspecific trait variation in plant communities. Ecol Lett 18:1406-1419. https://doi.org/10.1111/ele. 12508

Spasojevic MJ, Yablon EA, Oberle B, Myers JA (2014) Ontogenetic trait variation influences tree community assembly across environmental gradients. Ecosphere 5:1-20. https:// doi.org/10.1890/ES14-000159.1

Violle C, Enquist BJ, McGill BJ, Jiang L, Albert CH, Hulshof C, Jung V, Messier J (2012) The return of the variance: intraspecific variability in community ecology. Trends Ecol Evol 27:244-252. https://doi.org/10.1016/j.tree.2011. 11.014

Violle C, Navas M-L, Vile D, Kazakou E, Fortunel C, Hummel I, Garnier E (2007) Let the concept of trait be functional! Oikos 116:882-892. https://doi.org/10.1111/j.2007.00301299.15559.x

Visser MD, Bruijning M, Wright SJ, Muller-Landau HC, Jongejans E, Comita LS, de Kroon H (2016) Functional traits as predictors of vital rates across the life cycle of tropical trees. Funct Ecol 30:168-180. https://doi.org/10. $1111 / 1365-2435.12621$

Wright IJ, Reich PB, Westoby M, Ackerly DD, Baruch Z, Bongers F, Cavender-Bares J, Chapin T, Cornelissen JHC, Diemer M, Flexas J, Garnier E, Groom PK, Gulias J, Reich $\mathrm{PB}$, Oleksyn J, Ackerly DD, Baruch Z, Bongers F, Cavender-Bares J, Chapin T, Cornellissen JHC, Diemer M, Flexas J, Gulias J, Garnier E, Navas ML, Roumet C, Groom 
PK, Lamont BB, Hikosaka K, Lee T, Lee W, Lusk C, Midgley JJ, Niinemets Ü, Osada H, Poorter H, Pool P, Veneklaas EJ, Prior L, Pyankov VI, Thomas SC, Tjoelker MG, Villar R (2004) The worldwide leaf economics spectrum. Nature 428:821-827. https://doi.org/10.1038/ nature 02403

Wright JP, Ames GM, Mitchell RM (2016) The more things change, the more they stay the same? When is trait variability important for stability of ecosystem function in a changing environment. Philos Trans R Soc B Biol Sci. https://doi.org/10.1098/rstb.2015.0272
Yang LH, Rudolf VHW (2010) Phenology, ontogeny and the effects of climate change on the timing of species interactions. Ecol Lett 13:1-10. https://doi.org/10.1111/j.14610248.2009.01402.x

Publisher's Note Springer Nature remains neutral with regard to jurisdictional claims in published maps and institutional affiliations. 